\title{
LOS TALLERES DE POESÍA DEL MINISTERIO DE CULTURA EN LA NICARAGUA DE LOS AÑOS OCHENTA
}

\author{
Guadalupe Xocbitlanetzin Pastrana Hernández
}

\section{Resumen:}

El triunfo de la Revolución Popular Sandinista implicó para Nicaragua profundas transformaciones en distintos ámbitos, uno de ellos fue el cultural. Con la creación del Ministerio de Cultura, que tuvo como Ministro a Ernesto Cardenal, se impulsaron -entre otros proyectos-Talleres Populares de Poesía. Dar cuenta de la bistoria de estos Talleres, de sus formas de organización, de los poetas que en ellos participaron y que continúan escribiendo, e incluso bablar de la polémica que se desató entre la intelectualidad nicaragüense, porque a decir de algunos, los Talleres limitaban la creación poética en el país, es lo que se bace en este ensayo que además, pretende ser un aporte para entender e interpretar -desde otras miradas - a aquella Nicaragua recién liberada, aquella Nicaragua que a finales de los años ochenta (época en que en México y en otros países de América Latina se bablaba de neoliberalismo) constituyó un ejemplo de dignidad y rebeldía.

Palabras clave: poesía nicaragüense, poesía exteriorista, poesía popular, talleres de poesía.

\begin{abstract}
:
The victory of Sandinista Revolution involved deep transformation to Nicaragua in several fields, one of them Culture. With the creation of the Ministry of Culture, whose Minister was Ernesto Cardenal, - where carried out among other projects- Poetry Popular Workshops, Show the bistory of this workshops, its ways of organization, poets that were involved, that still writing. Also mention about the controversy between Nicaraguan intellectuals, due to some of them thought that workshops limited poetry creation, is one of the aims of this essay. As well aims make a contribution to understand and read into - from other perspectives - the new Nicaragua - that at the end of 80's decade (when Mexico and other Latin American countries was told of neoliberalism) was an example of dignity an rebellion.
\end{abstract}

Keywords: nicaraguan poetry, popular poetry, workshop poetry.

Reflexionar sobre la Nicaragua de principios de los años ochenta implica adentrarse en un proceso que, junto a otros de envergadura similar, marcó la historia no sólo de esta nación sino de la región centroamericana. El triunfo de la Revolución Popular Sandinista, en julio de 1979, implicó la caída de una dictadura de más de 40 años y una serie de transformaciones económicas, políticas, sociales y culturales.

En medio de un ambiente de crisis económica (por el endeudamiento y las graves pérdidas que había acarreado la lucha por el derrocamiento de la dictadura), de una elevada tensión social (derivada del surgimiento de grupos detractores del nuevo régimen apoyados por Estados Unidos), había esperanza porque se empezaba a construir una Nicaragua más igualitaria, justa y democrática, el gobierno revolucionario (constituido, en un principio, por la Junta de Gobierno de Reconstrucción Nacional, que dirigió Nicaragua de 1979 a 1985) dando impulso a una serie de proyectos con los que se buscaba acabar con el rezago educativo e involucrar a las clases populares en diferentes expresiones artísticas y culturales.

No se puede olvidar, por ejemplo, la Cruzada Nacional de Alfabetización (llevada a cabo de marzo a agosto de 1980) que redujo los índices de analfabetismo de un 50 a un 13\%, y que fue medular para que en el 2009, la UNESCO declarara a Nicaragua territorio libre de analfabetismo. Se debe recordar también la creación, el 20 de julio de 1979 (sólo un día después del triunfo de la Revolución), de la primera institución del Estado, en toda la historia de Nicaragua, dedicada a la cultura: el Ministerio de Cultura, que tuvo como Ministro al cura y poeta Ernesto Cardenal y como principal meta "el planteo, la ejecución y el desarrollo de una Política Cultural [...] respaldada en los principios de la Revolución Popular Sandinista” (Zamora: 1982; 277).

Basados en estos principios (y las líneas trazadas por medio de un discurso pronunciado por el Comandante Bayardo Arce en la inauguración de la Primera Asamblea de Trabajadores de la Cultura en febrero de 1980, 
reproducido bajo el título de "El difícil terreno de lucha: el ideológico",) Ernesto Cardenal y Daisy Zamora (Su Vice-Ministro de cultura de 1979 a 1982) señalaban que la nueva cultura nicaragüense debía ser un producto popular, desarrollar su rasgo revolucionario, ser nacional, anti-imperialista y democrática, y hacían énfasis en la necesidad de que el pueblo fuera un actor principal no sólo como consumidor de cultura, sino también como creador de bienes culturales (Zamora: 1982; 7).

Hay que tener claro, entonces, que el nuevo gobierno nicaragüense tenía una concepción sobre la cultura completamente distinta a la que imperó durante la dictadura de la familia Somoza, época en la que predominaron expresiones culturales externas (de origen norteamericano o europeo) que eran respaldadas por el grupo gobernante. Tras el triunfo de la Revolución se buscaba construir una nueva cultura (la cultura revolucionaria), que respondiera a intereses, ideales y aspiraciones de las clases populares; se decía que el triunfo revolucionario implicaba "el triunfo de la cultura de los explotados sobre la cultura de la burguesía" (Zamora: 1982; 7).

Para lograr estos objetivos y garantizar la participación de todos los nicaragüenses en el consumo y la creación de bienes culturales, el Ministerio de Cultura creó nueve programas de acción, representados por nueve instituciones fundamentales para el impulso cultural, entre las que se encontraban la Dirección de Enseñanza Artística, el Instituto Nicaragüense de Cine, el Instituto de Investigaciones Culturales y la Dirección de los Centros Populares de Cultura.

A través de la Dirección de los Centros Populares de Cultura se impulsaron talleres de Arte Popular en las áreas de música, teatro, danza, artes plásticas y literatura (específicamente Talleres de Poesía). Dentro de éstos, los Talleres de Poesía alcanzaron mayor relevancia y difusión. Ernesto Cardenal mencionaba, por ejemplo, que se hicieron -en diferentes universidades y periódicos del mundoinvestigaciones y reportajes al respecto (Cardenal: 1983; 13); y en su discurso de recepción de la Orden Rubén Darío, Julio Cortázar señaló que algunas personas, sobre todo en Europa, se asombraban por la importancia que tenían, en Nicaragua, los Talleres de Poesía (Cortázar: 1984; 48-51).

Al triunfo de la Revolución y con la fundación del Ministerio de Cultura, Ernesto Cardenal llamó a la poeta costarricense Mayra Jiménez para que se hiciera cargo de fundar Talleres de Poesía en toda Nicaragua (Cardenal: 1983; 14). Se trataba de Talleres dirigidos a las clases populares: acudían a ellos amas de casa, campesinos, obreros, estudiantes, pescadores, panaderos, guerrilleros, incluso personas recién alfabetizadas.

El primero de los Talleres se fundó el 22 septiembre de 1979 en Monimbó, comunidad que había jugado un papel importante en la resistencia y lucha contra la dictadura de los Somoza; a la semana siguiente se fundó el segundo, en Subtiava, y posteriormente en barrios populares de Managua, ciudades y pueblos; también se fundaron en batallones del ejército, unidades de policía, la Fuerza Aérea Sandinista y el Ministerio del Interior (Cardenal: 1983; 14).

Cabe señalar que aunque en un principio Jiménez era la única encargada de atender los Talleres, con el paso del tiempo la orientación se fue cediendo a poetas formados dentro de los mismos. De esta manera, Carlos Calero, Juan Ramón Falcón, Conny Pacheco, Gerardo Gadea, Gonzalo Martínez y Marvin Ríos, quienes iniciaron como poetas de Taller, llegaron a ser orientadores y a participar como miembros del Consejo Editorial de la revista Poesía libre, cuyo responsable era el escritor Julio Valle-Castillo, que además dirigía el Departamento de Literatura del Ministerio de Cultura.

El éxito de estos Talleres fue tal que a finales de 1981 (del 18 al 20 de diciembre) se llevó a cabo, en Palacagüina, el Primer Encuentro Nacional de los Talleres de Poesía; en él participaron entre 200 y 300 jóvenes de todo el país, que además de compartir sus experiencias y leer sus poemas, hicieron grupos de trabajo para discutir sobre literatura.

Para 1984 Mayra Jiménez hablaba de una generación de "alrededor de 645 jóvenes poetas" (Trobo: 1985; 146), y a finales de 1985 se decía que "sesenta talleres trabajaban activamente [...] con el apoyo de nueve poetas orientadores" (Benavides: 1988). Sin embargo, de acuerdo con Karyn Hollis (investigadora norteamericana que hizo, en los años ochenta, un estudio sobre los Talleres) el punto más alto fue en noviembre de 1982 -cuando "66 de ellos habían sido formalmente organizados con un total de 627 poetas"-(Hollis: 1991; 20) y a partir de ese momento su número fue disminuyendo (debido, quizás, a la difícil situación económica, política y social que atravesaba Nicaragua), hasta que en 1988, con la desaparición del Ministerio de Cultura, desaparecieron también los Talleres de Poesía.

Pero, ¿cuál era el origen de estos Talleres? Los Talleres impulsados por el Ministerio de Cultura 
tenían como antecedente un primer Taller llevado a cabo en Solentiname (lugar al que llegó Ernesto Cardenal en 1966 con el objetivo de fundar una comunidad contemplativa) entre los años 1976 y 1977 en el que participó, además de Cardenal, la poeta Mayra Jiménez. De aquella primera experiencia se publicó, ya en 1980, la antología Poesía Campesina de Solentiname.

Al estudiar la experiencia del Taller de Solentiname se encuentran varios elementos que sirven para entender la dinámica de los Talleres posteriores y la poesía que escribieron quienes asistían a ellos; por esta razón, resulta fundamental contemplar, dentro de cualquier estudio sobre los Talleres del Ministerio de Cultura, aquella primera experiencia.

Al igual que los Talleres del Ministerio de Cultura, el de Solentiname estaba dirigido a las clases populares: "acudían trabajadores humildísimos, campesinos sabios, jóvenes de las barriadas, policías de escolta y soldados sandinistas" (Cardenal. 1983; 14); existen, además, coincidencias en cuanto a las edades de los asistentes: si en el Taller de Solentiname habían participado, principalmente, hombres y mujeres jóvenes (incluso niños, como queda testificado en Poesía Campesina de Solentiname, en donde se incluyen poemas de niños de cinco, siete, diez y once años) en los Talleres posteriores ocurrió algo similar: quienes más se interesaron eran jóvenes "entre los diecisiete y los veinticuatro años, algunos de catorce y quince, algunos niños de once y doce años, y muy pocos adultos que se asimilaron con un excelente espíritu crítico" (Trobo: 1985; 146).

Un ejemplo (respecto a la edad) que sorprendió a muchos y del que -en una entrevista- habló con emoción la poeta Vidaluz Meneses es el de Grethel Cruz, una joven de apenas 14 años que "publicó algunos buenos poemas de principiante"' , mismos que se incluyeron (además de en periódicos, revistas y suplementos culturales de la época) en una antología elaborada por Daisy Zamora (publicada ya en los años 90) titulada La mujer nicaragüense en la poesía, en la que se contempla a poetas como Conny Pacheco, Alba Azucena Torres, Isidra Ortiz (las tres poetas de Taller), y Rosario Murillo, Gioconda Belli, Gloria Gabuardi, la misma Meneses, entre otras.

De Solentiname se retomó también la metodología para la creación y el análisis de los poemas. Dentro de las prácticas que volvieron a presentarse se

1 Entrevista a Vidaluz Meneses, Managua, Nicaragua, 20 de marzo de 2014.

2 Entrevista a Carlos Calero, San José, Costa Rica, 6 de mayo de 2014. encuentran, por ejemplo, la discusión grupal de los poemas y el ejercicio de la lectura.

A propósito de la discusión grupal de los poemas, Mayra Jiménez explica que (en el caso del Taller de Solentiname) en un principio los poemas se discutían entre el autor y ella, pero siempre con la presencia de otros integrantes, y posteriormente se comenzaron a discutir en grupo (Jiménez: 1980; 9). Por su parte, Carlos Calero (quien asistió a uno de los Talleres formados por el Ministerio de Cultura, el de Monimbó, y tiempo después trabajó como orientador) platica que ya en estos Talleres "alguien proponía uno de sus poemas, luego se leía y la mayoría comentaba acerca del lenguaje poético, si se abordaba bien el tema, que no hubiera repeticiones innecesarias, rimas buscadas, abuso de metáforas muy oscuras" ${ }^{2}$; señala, además, que en la sesiones se leía a autores como Fernando Silva, Ernesto Cardenal, Constantino Cavafis, Safo, William Carlos Williams, Edgar Lee Masters, Carl Sandburg y Walt Whitman.

Pero el fomento a la lectura no sólo se limitaba al tiempo y espacio de los Talleres, también en la revista Poesía libre (principal órgano difusor del trabajo de los poetas de Taller) se asignaba un importante espacio (la mitad de la revista, que generalmente tenía entre 50 y 60 páginas) a la presentación de poesía de todo el mundo. Si se hace una revisión de los distintos números se descubre que se publicaban desde poetas como Leonel Rugama y muchos de los que a decir de Calero se leían en los Talleres, hasta José Agustín Goytisolo, Roberto Paredes, Armando Orozco Tovar, Luis Rogelio Nogueras y Ariel Dorfman; así como selecciones de poesía palestina de combate, poemas anónimos salvadoreños, poesía de los indios sioux, poesía japonesa, de Oceanía y esquimal; y existen números dedicados a la poesía femenina, en donde se incluye a Nancy Morejón, Mayra Jiménez, Gioconda Belli, Rosario Murillo, Vidaluz Meneses, Daisy Zamora y Luz Marina Acosta.

En cuanto a la poesía que se escribió en el Taller de Solentiname y la que se escribió en los Talleres de los años 80 , se puede señalar que ambas son temáticamente próximas al mundo campesino (lo cual es razonable si pensamos en el origen de quienes la escribían); las caracteriza una sencillez en el lenguaje, el uso de palabras coloquiales, la ausencia de rima y la predilección por el verso libre.

En Solentiname, cuando la vida cotidiana era la pesca y el trabajo en el campo, los poetas "empezaron a rescatar todos los pájaros, sus lagos, sus ríos, sus archipiélagos, su cielo, todo ese mundo que era su 
realidad" (Trobo: 1985; 144); y cuando muchos de aquellos jóvenes se involucraron en la guerrilla y la realidad se convirtió en una lucha frontal contra la Guardia Nacional, la temática cambió: se empezó a hablar de la guerra, de los campamentos guerrilleros, de la ausencia, del abandono, de la muerte.

Y en los poemas de los Talleres del Ministerio, escritos cuando ya la Revolución había triunfado, se hablaba, entre otros temas, del amor, de la esperanza, de las campañas de alfabetización, de la construcción de una nueva Nicaragua. Si se hace un análisis de esta poesía, si se estudian las características señaladas, se descubre que muchas de ellas están presentes en la poesía a la que José Coronel Urtecho y Ernesto Cardenal llamaron exteriorista, y que no es más que la poesía "creada con las imágenes del mundo exterior, el mundo que vemos y palpamos [...] El exteriorismo es la poesía objetiva: narrativa y anecdótica, hecha con los elementos de la vida real y con cosas concretas, con nombres propios y detalles precisos y datos exactos y cifras y hechos y dichos" (Cardenal: 1975; VIII).

La influencia de Ernesto Cardenal y del exteriorismo es innegable. Para poetas como Carlos Calero está claro que desde lo leído se hacía énfasis en la poesía exteriorista, concreta, coloquial, conversacional ${ }^{3}$. Se puede decir, entonces, que el exteriorismo se fomentó, en primer lugar, a través de las lecturas que se hacían en los Talleres y las que se recomendaban en Poesía libre; pero además (y este es un dato fundamental) a través de la difusión (desde el Taller de Solentiname) de un manual escrito por Cardenal titulado "Unas reglas para escribir poesía", que se publicó de manera íntegra en marzo de 1980 en el diario Barricada, órgano oficial del FSLN.

Aquel manual para escribir poesía contiene apenas siete reglas en las que se invita, por ejemplo, a escribir como se habla, evitar el uso de la rima, de frases altisonantes y "palabrería”; y se aconseja evitar lugares comunes y privilegiar, más que las ideas, la descripción de "cosas" que entran por los sentidos: que se tocan, que se gustan, que se ven, que se huelen (Cardenal: 1980; 11). No se trata, pues, de reglas en el estricto sentido de la palabra, sino de una especie de recomendaciones que tienen una relación directa con lo que para Cardenal es la poesía y con su declarado principio de que, para él, "la única poesía que puede expresar la realidad latinoamericana, y llegar al pueblo, y ser revolucionaria, es la exteriorista" (Cardenal: 1975; IX).

De acuerdo con Carlos Calero y Juan Ramón Falcón (ambos poetas de Taller y orientadores) en los Talleres del Ministerio de Cultura el manual se tomaba como parte de las recomendaciones básicas para los poetas, sin que se limitaran la creatividad, la temática o el estilo. Para Falcón, fue escrito por Cardenal con un afán, más bien, didáctico, y en los Talleres nunca funcionó como una fórmula que se aplicara de manera tajante en los poemas ${ }^{4}$. Por su parte, Calero comenta:

Las famosas "Reglas para escribir poesía" de Ernesto Cardenal siento que funcionaban como un manual elemental y básico para motivar la escritura. Eso era lo importante, que el 'tallerista' contara, dijera algo de su vida personal y colectiva. Insisto que eran un instrumento básico, pues con el tiempo yo mismo me di cuenta, seguro por mi afán de buscar mi propia voz, que las estaba sobrepasando, en el sentido que debía buscar otros elementos poéticos para fundamentar lo que en mi individualidad empezaba a buscar como poeta 5 .

Precisamente la influencia de Ernesto Cardenal y del exteriorismo en los poetas de los Talleres del Ministerio de Cultura fue uno de los puntos más criticados por un grupo de poetas que publicaron (bajo el nombre "Entre la libertad y el miedo" en 1981 en Ventana, suplemento cultural del diario Barricada) una conversación entre los miembros del Consejo de Dirección de este suplemento (Rosario Murillo, Guillermo Rothschuh Villanueva, Francisco de Asís Fernández y Gioconda Belli) y los escritores invitados Eduardo Galeano, Juan Gelman y Claribel Alegría, en la que se manifestó una preocupación (por parte del Consejo de Dirección) porque los Talleres generaran, a largo plazo, una uniformidad en la poesía nicaragüense a través de la agigantada influencia de Ernesto Cardenal y de la poesía exteriorista.

A raíz de esta crítica se publicó (por parte de los miembros y orientadores de los Talleres de Poesía) una carta-respuesta (con el título "Los talleres de poesía responden") en la que se reprochaba a los integrantes del Consejo de Dirección de Ventana el haber cuestionado los Talleres sin antes acercarse para conocer, desde el fondo, su metodología; así como se señalaba que jamás se les había forzado a escribir de una sola forma: el exteriorismo, y mucho menos sobre un sólo tema: la Revolución.

Después de estas publicaciones se hicieron otras

3 Entrevista a Carlos Calero, San José, Costa Rica, 6 de mayo de 2014.

4 Entrevista a Juan Ramón Falcón, Masaya, Nicaragua, 9 de junio de 2014.

5 Entrevista a Carlos Calero, San José, Costa Rica, 6 de mayo de 2014. 
(para defender o acusar a los poetas de Taller y a Ernesto Cardenal) que alargaron la polémica al menos durante todo 1981. Aunque en un primer momento esta polémica puede parecer un tema sin relevancia, para investigadores como Ginés Bonillo Martínez el destino de los Talleres y los poetas que en él se formaron tiene una relación directa con aquellos hechos (Bonillo: 1996; 1). En la actualidad, por ejemplo, se habla muy poco de los Talleres Populares de Poesía y de su influencia en la literatura nicaragüense de los años ochenta, y cuando se hace hay cierta minimización de su importancia o estigmatización de los poetas que se formaron en ellos; se trata, además, de uno de aquellos temas que deben abordarse con sumo cuidado para no reanimar antiguas diferencias.

El fondo de la polémica sobre los Talleres de Poesía tenía que ver, a decir del poeta Carlos Calero, con una mala relación entre el Ministerio de Cultura (con Ernesto Cardenal a la cabeza) y la Asociación Sandinista de Trabajadores de la Cultura (de la que era Secretaria General Rosario Murillo) ${ }^{6}$.

Juan Ramón Falcón coincide con el punto de vista de Calero, y agrega que la ASTC era una especie de Ministerio de Cultura pero con mucho más poder (sin que tuviera la categoría de Ministerio) y que no se dirigía a los sectores populares, sino tenía entre sus filas a los "profesionales de la cultura", hombres y mujeres que trabajaban al lado de Rosario Murillo, que estaban estrechamente vinculados a esta Asociación, y que llegaron a manifestar críticas respecto a la forma en que Cardenal estaba manejando el Ministerio de Cultura ${ }^{7}$.

Se puede inferir que la crítica a los Talleres Populares de Poesía no era más que la expresión de un problema mucho más profundo: una serie de discrepancias entre la concepción de Cardenal y la de Murillo acerca del quehacer cultural en aquella Nicaragua en reconstrucción, una forma distinta de entender y de impulsar la llamada "cultura revolucionaria".

Los Talleres fueron entonces sólo una de las ventanas desde las que se mostraron las diferencias conceptuales, ideológicas, etcétera, entre quienes impulsaban el proyecto revolucionario. Estas divergencias (que de alguna manera culminaron con la abolición -en 1988, cuando era presidente Daniel Ortega- del Ministerio de Cultura y la creación -en febrero de 1989- del Instituto de Cultura, a cargo

6 Entrevista a Carlos Calero, San José, Costa Rica, 6 de mayo del 2014

7 Entrevista a Juan Ramón Falcón, Masaya, Nicaragua, 9 de junio del 2014

8 Entrevista a Vidaluz Meneses, Managua, Nicaragua, 20 de marzo de 2014.

Guadalupe Xochitlanetzin Pastrana Hernández de Rosario Murillo) fueron abordadas de manera detallada por el holandés Klaas S. Wellinga en su libro "Entre la poesía y la pared".

Pero más allá de revivir viejas polémicas, o de tomar una posición a favor o en contra de los Talleres (lo cual sería, incluso, anacrónico), es indispensable tratar de verlos en su justa dimensión; ser conscientes de sus limitaciones y de sus aportes.

Es verdad que muchos de los hombres y mujeres que asistieron a los Talleres Populares de Poesía no continuaron publicando (aunque no sabemos si escribiendo), es verdad también que debido, quizás, a la inestabilidad económica por la que atravesaba Nicaragua y al poco presupuesto con el que contaba el Ministerio de Cultura, no se dio seguimiento ni apoyo a los talleristas que deseaban continuar su formación como poetas o estudiar una licenciatura afín a la literatura; no obstante, en estos Talleres se formó a una gran generación de lectores, y fueron un elemento fundamental en la alfabetización.

Los Talleres de Poesía fueron un proyecto cultural con el que se logró que campesinos, obreros, soldados, amas de casa, pescadores, etcétera, pudieran acercarse a mucha de la más bella literatura universal, a lecturas que en otras condiciones (por ejemplo en la desigualdad, pobreza, marginación y represión que se vivía durante la dictadura) no habrían llegado a sus manos. Procurar el acercamiento de los nicaragüenses a algunas de las más elevadas expresiones artísticas es uno de los logros del Ministerio de Cultura que dirigió Ernesto Cardenal.

Por otra parte, la poesía que escribieron los poetas de taller (sin analizar en este momento su calidad literaria o falta de ella) da cuenta del proceso revolucionario por el que atravesó Nicaragua, es un testimonio de aquella década de transformaciones, es además, una recopilación de vivencias, emociones, dolores, esperanzas y sueños de las clases populares nicaragüenses, las mismas que durante más de cuarenta años fueron soslayadas.

De los Talleres Populares de Poesía sobreviven poetas como Alba Azucena Torres, Marvin Ríos, Juan Ramón Falcón (quien ha colaborado con Ernesto Cardenal en un Taller de Poesía para niños con cáncer que se imparte en el hospital "La Mascota", en Managua), Bosco Centeno, William Valle Picón y Carlos Calero. Este último (quien es, para la poeta Vidaluz Meneses, "uno de los grandes logros de los Talleres" ") ha publicado libros como El humano oficio, La costumbre del reflejo, Paradojas de la 
mandibula, Geometrías del cangrejo y Arquitecturas de la sospecha. Su poesía, alejada ya del exteriorismo, requiere de una investigación a fondo. Quedan también una serie de antologías publicadas en los años ochenta por el Ministerio de Cultura: Poesía Campesina de Solentiname (1980), Poesía de la nueva Nicaragua. Talleres populares de poesía (1983), Fogata en la oscurana (1985) y Poesía de las fuerzas armadas (1985). Sólo resta agregar que este ensayo es apenas un fragmento de una investigación mucho más amplia con la que se pretende aportar al entendimiento de la Nicaragua de fines del siglo pasado; este ensayo es apenas una compilación de datos y anécdotas sobre los Talleres de Poesía del Ministerio de Cultura, apenas un intento de revalorar una experiencia significativa del proyecto cultural sandinista. Hace falta mucho: reflexionar sobre el valor literario de esta poesía, adentrarse en su valor testimonial, reivindicar y estudiar el trabajo de poetas que se formaron en estos Talleres y que siguen escribiendo.

El éxito que durante los años ochenta tuvo este proyecto está relacionado, desde mi punto de vista, con lo que Julio Cortázar definió como una sed y voluntad de cultura del pueblo nicaragüense (Cortázar: 1984; 49). Aquella oleada de hombres y 22 mujeres que desacralizaron el adjetivo "poeta" y soñaron con una Nicaragua diferente, no era más que la muestra de las ansias de expresión de un pueblo que durante más de cuarenta años había sido obligado a guardar silencio, un pueblo que por fin se reapropiaba de su palabra y que, además, la transformaba en poesía.

Recibido: 12 de marzo, 2015

Aceptado: 25 de mayo

\section{Referencias bibliográficas}

Cardenal, E. (1983). “Talleres de poesía: socialización de los medios de producción poéticos” en Poesía de la nueva Nicaragua. Talleres populares de poesía. México: Siglo XXI.

Cardenal, E. (1975). "Prólogo a Poesía Nicaragüense" en Poesía Nicaragüense. Nicaragua: Ediciones el pez y la serpiente.

Cortázar, J. (1984). "Discurso de recepción de la Orden Rubén Darío" en Nicaragua tan violentamente dulce. Argentina: Muchnik Editores.

Hollis, K. (1991). Poesía del pueblo para el pueblo. Talleres nicaragüenses de poesía. Costa Rica: CSUCA.

Jiménez, M. (1980). "Prólogo a Poesía Campesina de Solentiname" en Poesía Campesina de Solentiname. Managua: Publicaciones del Mi nisterio de Cultura.

Trobo, C. (1985) Lo que pasa en Nicaragua. Nicaragua: Editorial Nueva Nicaragua.

Zamora, D., Valle-Castillo, J. (1982). Hacia una politica cultural de la revolución popular sandinista. Managua: Ministerio de Cultura.

\section{Hemerografía}

Benavides, Pedro Pablo, 1988, "Zigzagueos de la cultura, proceso de autoevaluación”, Envío, No. 87.

Bonillo Martínez, Ginés, 1996, "Los talleres de poesía. Entre el recuerdo y el olvido", Nuevo Amanecer Cultural, XVI-No. 808, 1 y 6.

Cardenal, Ernesto, 1980, "Para escribir poesía", Barricada. 